\title{
Recurrence of adrenal aldosterone-producing adenoma
}

\author{
José María Calvo-Romero, Juan Lucio Ramos-Salado
}

\begin{abstract}
Summary
Conn's syndrome (adrenal aldosteroneproducing adenoma) and bilateral adrenal hyperplasia are the most common causes of primary aldosteronism. The treatment of choice for patients with aldosteroneproducing adenoma is unilateral total adrenalectomy. Recurrence after adequate surgery is exceptional. We present a patient with recurrence of an aldosterone-producing adenoma in the right adrenal gland 9 years after adenomectomy of a aldosterone-producing adenoma in the same adrenal gland. We conclude that adenomectomy is not an adequate therapy for patients with adrenal aldosterone-producing adenoma.
\end{abstract}

Keywords: aldosteronism; adenoma; Conn's syndrome; adrenomectomy

Hypertension, hypokalaemia, suppressed plasma renin activity and elevated serum aldosterone levels characterise primary aldosteronism. Prevalence estimates for primary aldosteronism vary from $0.05 \%$ to $2 \%$ of the hypertensive population. ${ }^{1}$ Adrenal aldosteroneproducing adenoma (APA) and bilateral adrenal hyperplasia (BAH) are the most common causes of primary aldosteronism. ${ }^{1}$ The treatment of choice for patients with APA is unilateral total adrenalectomy and for patients with BAH should be pharmacologic. ${ }^{1}$ The recurrence of an adrenal APA after adequate surgery is exceptional. We present a patient with recurrence of an adrenal APA after adenomectomy.

\section{Case report}

A 62-year-old woman was admitted to the hospital because of severe hypokalaemia and poorly controlled hypertension. She underwent adenomectomy for primary aldosteronism due to right APA 9 years ago. The pathological examination revealed a $2-\mathrm{cm}$ diameter adenoma without other abnormalities. After surgery, she had been asymptomatic with normotension and normokalaemia without pharmacologic treatment. In the follow-up, repeated plasma renin activity and serum aldosterone levels were normal. Six months before admission, hypertension resistant to antihypertensive polytherapy, weakness and paraesthesias developed. At entry, her medications comprised fosinopril (20 mg daily), amlodipine (10 mg daily) and hydrochloro- tiazide (25 mg daily). There was no family history of hypertension. A physical examination showed only moderate obesity. The blood pressure was $160 / 110 \mathrm{mmHg}$. Blood chemistry showed: urea $4.3 \mathrm{nmol} / 1$, creatinine $52 \mu \mathrm{mol} / 1$, sodium $143 \mathrm{mmol} / \mathrm{l}$, potassium $2.4 \mathrm{mmol} / \mathrm{l}$ and chloride $96 \mathrm{mmol} / \mathrm{l}$. Haematology, chest X-ray and electrocardiogram were normal. Antihypertensive therapy was discontinued and potassium chloride supplements were given. On the following days, mild hypokalaemia (3-3.1 $\mathrm{mmol} / \mathrm{l}$ ) persisted, blood $\mathrm{pH}$ was 7.50 and $\mathrm{HCO}_{3}^{-} 37 \mathrm{mmol} / 1$. The 24-hour urinary potassium was $67 \mathrm{mmol}$. On free dietary sodium intake, measured supine at $08.00 \mathrm{~h}$ before she arose, plasma aldosterone concentration was $3575 \mathrm{pmol} / 1$ (normal range 41-412 pmol/1) and plasma renin activity was undetectable. Upright at $08.00 \mathrm{~h}$, plasma aldosterone concentration and plasma renin activity were 2550 $\mathrm{pmol} / \mathrm{l}$ (137-825 pmol/1) and undetectable, respectively. Plasma aldosterone concentration before and after saline loading was $3230 \mathrm{pmol} / 1$ and $3055 \mathrm{pmol} / 1$, respectively. The 24-hour urinary free cortisol was $120 \mathrm{nmol}$ (75-250 $\mathrm{nmol})$. The $08.00 \mathrm{~h}$ basal cortisol was 223 $\mathrm{nmol} / 1$ (140-690 nmol/1). The $08.00 \mathrm{~h}$ cortisol after dexamethasone suppression (1 $\mathrm{mg}$ at $23.00 \mathrm{~h}$ ) was $47 \mathrm{nmol} / \mathrm{l}$. The 24 -hour urinary free catecholamines, dopamine, epinephrine and norepinephrine were normal. Adrenal computed tomography (CT) showed a $3-\mathrm{cm}$ diameter hypodense nodule without enhancement after intravenous contrast in the right adrenal gland and a normal left adrenal gland (figure 1). Magnetic resonance imaging (MRI) demonstrated the same right adrenal nodule

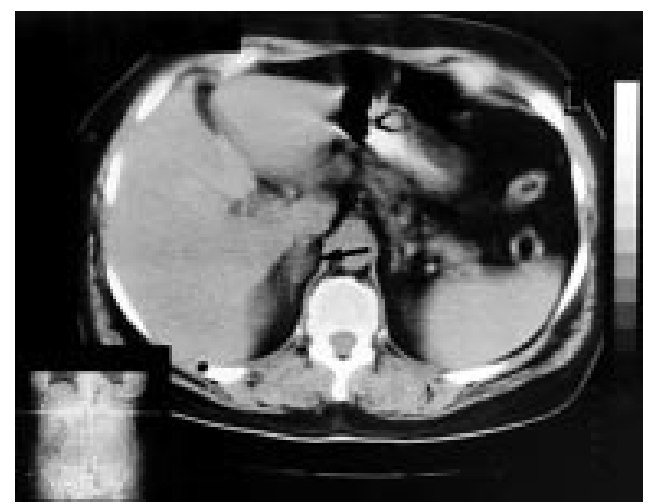

Figure 1 Adrenal CT without intravenous contrast: 3-cm diameter hypodense nodule in right adrenal gland (arrow) 


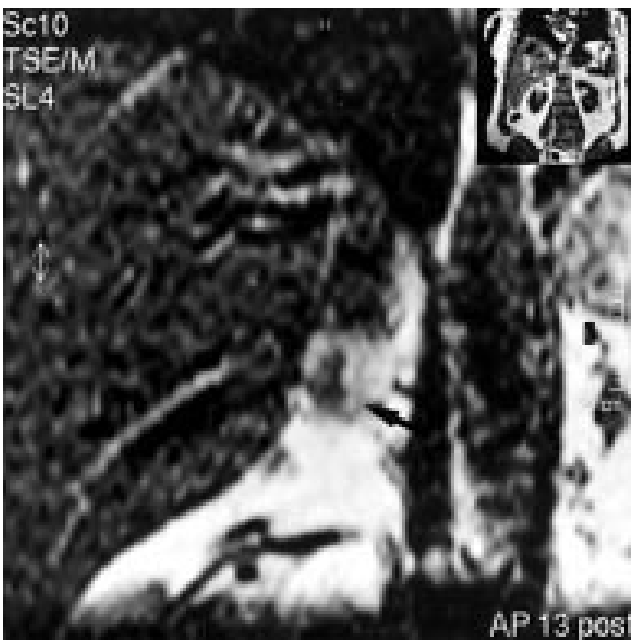

Figure 2 Adrenal MRI (coronal T2-weighted image): $3-\mathrm{cm}$ diameter isointense nodule without destruction of the gland and with a hyperintense rim (arrow)

with isointensity in $\mathrm{T} 1$ and $\mathrm{T} 2$-weighted sequences without destruction of the gland and with a hyperintense rim (figure 2).

The patient received spironolactone $(100 \mathrm{mg}$ daily) and normotension and normokalaemia were achieved without potassium supplements. A total right adrenalectomy was carried out. The pathological examination of the gland revealed a 3-cm diameter adenoma without other abnormalities. After adrenalectomy, plasma aldosterone concentration and plasma renin activity normalised and potassium levels remained normal without spironolactone. Two years after surgery, she was asymptomatic and normotensive without pharmacologic therapy, and plasma aldosterone concentration, plasma renin activity and potassium levels were normal.

\section{Discussion}

We describe the recurrence of an adrenal APA 9 years after adenomectomy, which is extremely rare ${ }^{2}$; to our knowledge, only two such cases have previously been reported in the literature. ${ }^{2}$

The resected adrenal gland sometimes contains macro- or micro-nodular lesions in addition to APA. ${ }^{4}$ These nodules are multiple and

1 Litchfield WR, Dluhy RG. Primary aldosteronism. Endocrinol Metab Clin North Am 1995;24:593-612.

2 Martinot JC, Lecomte-Houcke M, Gonzales C, et al. Results of unilateral adrenalectomy for primary hyperaldosteronism. Ann Chirurg 1994;48:911-6.

3 Blumenfeld JD, Sealey JE, Schlussel Y, et al. Diagnosis and treatment of primary aldosteronism. Ann Intern Med 1994;121:877-85

4 Doppman JL. The dilemma of bilateral adrenocortical nodularity in Conn's and Cushing's syndromes. Radiol Clin North Am 1993;31:1039-50.

5 Doppman JL, Gill JR Jr. Hyperaldosteronism: sampling the Doppman JL, Gill JR Jr. Hyperaldosteron
adrenal veins. Radiology 1996;198:309-12.

6 Guerin CK, Wahner HW, Gorman CA, et al. Computed Guerin CK, Wahner HW, Gorman CA, et al. Computed
tomography scanning versus radioisotipe imaging in tomography scanning versus radioisotipe imaging
adrenocortical diagnosis. Am $\mathcal{F}$ Med 1983;75:653-7. generally bilateral and lead to a more complex differential diagnosis than the presence of a unilateral solitary mass. This bilateral nodularity is not synonymous with hyperplasia, and adrenal venous sampling is required to detect cases of surgically correctable APA. ${ }^{5}$ The clinical significance of these nodular lesions in patients with APA is not fully clear. They are not thought to contribute to recurrence but to result from intractable hypertension. ${ }^{4}$ The pathological examination of the adrenal gland in our patient revealed no abnormalities other than the adenoma.

Adrenal scintigraphy with iodo-cholesterol has assisted in distinguishing APA from BAH. Unilateral accumulation of the isotope characterises APA. Adrenal CT is simpler and less expensive than adrenal scintigraphy. In addition, the sensitivity and positive predictive value for APA of scintigraphy and CT are similar, at approximately $70 \% .^{167}$ The sensitivity of scintigraphy is largely dependent on the size of the adenoma, and it is unlikely that diagnostic information will be obtained if findings are normal on the CT scan. ${ }^{67}$ Adrenal adenomas can be differentiated from metastases by adrenal MRI. A hyperintense rim in T1- and T2-weighted sequences is characteristic for adenomas, ${ }^{8}$ as in our case. Biochemical tests also aid in differentiating the type of primary aldosteronism. The absence of the normal postural increase in plasma aldosterone concentration supports the diagnosis of APA, with a diagnostic accuracy of $85 \%{ }^{1}$

The treatment of choice for patients with APA is unilateral total adrenalectomy. ${ }^{13}$ Some authors debate whether a tumour-bearing adrenal gland should be removed totally or whether adenomectomy is curative. Our patient underwent adenomectomy and recurrence in the same adrenal gland developed 9 years later. We believe that total adrenalectomy should always be performed for APA.

Surgery of APA cures primary aldosteronism, although persistent hypertension, usually mild, occurred in $11-31 \%$ of patients. ${ }^{12}$ Risk factors for persistent hypertension after surgery are age at surgery, poor response to spironolactone treatment, and long duration of hypertension prior to surgery. ${ }^{10}$ In our case, there was a short history of hypertension and a good response to spironolactone, and hypertension was cured on a 2-year follow-up after second surgery.

7 Hogan MJ, McRae J, Schambelan M, et al. Location of
aldosterone-producing adenomas with ${ }^{131} \mathrm{I}-19-$
iodocholesterol. N Engl f Med 1976;294:410-4.
8 Ichikawa T, Ohmoto K, Uchiyama G, et al. Adrenal
adenoma: characteristic hyperintensive rim sign on fat-
saturated spin-echo MR images. Radiology 1994;193:247-
50.
$9 \begin{aligned} & \text { Streeten DH, Andersen GH Jr, Wagner S. Effect of age on } \\ & \text { response of secondary hypertension to specific treatment. } \\ & \text { Am f Hypertens 1990;3:360-5. }\end{aligned}$
$\begin{aligned} & \text { Obara T, Ito Y, Okamoto T, et al. Risk factors associated } \\ & \text { with postoperative persistent hypertension in patients with } \\ & \text { primary aldosteronism. Surgery 1992;112:987-93. }\end{aligned}$ 